\title{
Hydride-like $\mathrm{NH}_{2}{ }^{\delta-}$ species-driven reductive amination over Co@CoO catalyst
}

Wanjun Guo ${ }^{1,2}$, Zhi-Qiang Wang ${ }^{1,2}$, Shuang Xiang ${ }^{1}$, Yaxuan Jing ${ }^{1 *}$, Yong Guo ${ }^{1}$, Xiaohui Liu $^{1}$, Xue-Qing Gong ${ }^{1 *}$ and Yanqin Wang ${ }^{1 *}$

${ }^{1}$ Key Laboratory for Advanced Materials and Joint International Research Laboratory of Precision Chemistry and Molecular Engineering, Feringa Nobel Prize Scientist Joint Research Center, Research Institute of Industrial Catalysis, School of Chemistry and Molecular Engineering, East China University of Science and Technology, Shanghai, 200237, China.

${ }^{2}$ These authors contributed equally.

Corresponding authors: jingyaxuan@ecust.edu.cn (Y. X. J.); xgong@ecust.edu.cn (X. Q. G.); wangyaqin@ecust.edu.cn (Y. Q. W.)

\begin{abstract}
Selective synthesis of primary amines via reductive amination becomes an important research topic due to their wide applications. Various metal-based catalysts (Ru, Ir, Pt, Rh, etc.) have been developed; however, most systems suffer from low efficiency and poor stability. Here, we revealed that the hydride-like $\mathrm{NH}_{2}{ }^{{ }^{-}-}$species, generated by the dissociation of $\mathrm{NH}_{3}$ over a core-shell structured Co@CoO catalyst is capable of accelerating the ammonolysis of Schiff bases, the reaction intermediates. This catalyst can handle various reductive aminations of aldehydes and ketones under mild conditions and run 21 times without deactivation. The combination of various spectroscopic measurements and computational modelling illustrated that this catalyst not only drives the dissociation of $\mathrm{H}_{2}$ to active $\mathrm{H}^{\delta-}$ species, it also enables the
\end{abstract}


homolytic and heterolytic cleavages of $\mathrm{NH}_{3}$ to $\mathrm{NH}_{2}{ }^{\delta-}$ species. $\mathrm{D}_{2}$ isotopic tracing experiment provided further evidence of the direct participation of hydride-like $\mathrm{NH}_{2}{ }^{{ }^{-}-}$species in the ammonolysis of the Schiff bases. Theoretical calculations also verified the stable co-adsorption state of the $\mathrm{H}^{\delta-}$ and $\mathrm{NH}_{2}{ }^{\delta-}$ species which allows the Schiff base to move freely on the surface of the $\mathrm{CoO}$ shell, resulting in the exceptional catalytic activity. This study demonstrates, for the first time, the potential of metal-oxide catalysts for the production of primary amines through reductive amination.

\section{Introduction}

Amines, in particular primary amines, are widely used for the synthesis of dyes, surfactants, polymers, pharmaceuticals, and agrochemicals, profoundly shaping the landscape of the chemical industry. ${ }^{1-7}$ In the last decades, catalytic reductive amination of biomass-derived carbonyl compounds (furfural, cyclopentanone, HMF, etc.) to obtain primary amines has drawn particular attention, providing grand opportunities for the sustainable production of amines from renewable energy $y^{1,2,5,8-13}$

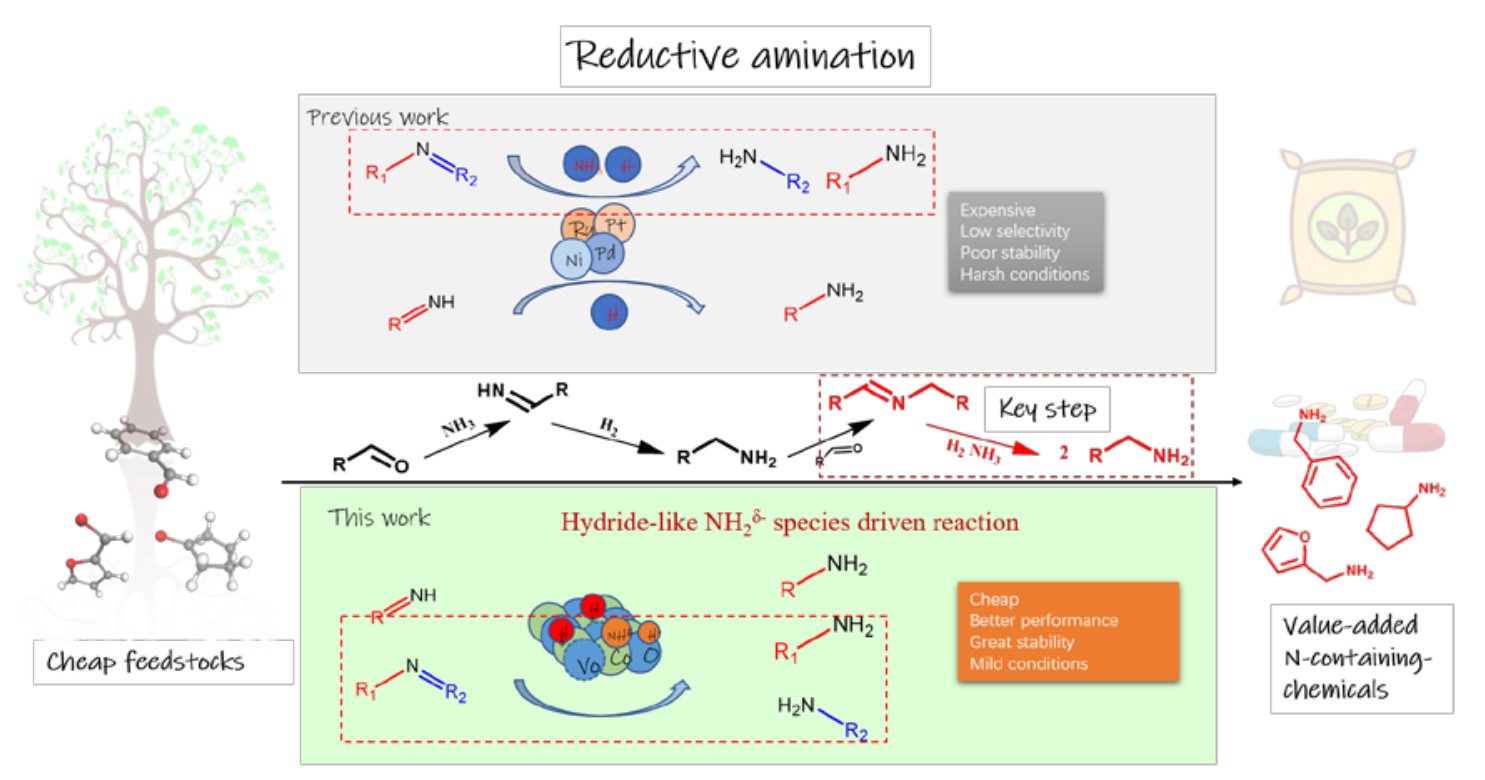

Scheme 1. Comparison of catalytic mechanisms between noble metal catalysts and Co@CoO. 
The reductive amination of carbonyl compounds undergoes the direct amination of aldehydes/ketones with $\mathrm{NH}_{3}$ to imines and its subsequent hydrogenation. In the process, the formation of Schiff bases is inevitable through the dehydration of substrate and primary amines due to the stronger nucleophilicity of primary amine products than that of $\mathrm{NH}_{3}{ }^{14-17}$ Previous studies demonstrated that Schiff bases were accumulated in large quantities at the beginning and then converted into corresponding primary amines, directly determining the rate of the reductive amination. ${ }^{14,17}$ Noteworthy, the Schiff bases intermediates require the further ammonolysis to boost the selective production of primary amine products. Therefore, a key challenge of this task is to design a catalyst that enables the dissociation of $\mathrm{NH}_{3}$. Meanwhile, with the help of $\mathrm{H}$ species dissociated on the designed catalyst, the highly efficient and selective production of primary amine products can be achieved.

Reductive amination was usually catalyzed by supported metal (Ru, Ir, Pt, Rh, Ni, etc.) catalysts. ${ }^{17-29}$ It is widely recognized that the free radicals $(\mathrm{H} \cdot)$ generated by homolytic dissociation of $\mathrm{H}_{2}$ on the metallic species of these catalysts participate in the hydrogenation of imine during reductive amination. ${ }^{30}$ Compared with the $\mathrm{H} \cdot$ species, the $\mathrm{H}^{\delta-}$ species generated through heterolytic dissociation of $\mathrm{H}_{2}$ on single atom catalysts or metal oxide catalysts with oxygen vacancies were recently proved to have better catalytic performance. ${ }^{31-35}$ Inspired by the catalysis involving $\mathrm{H}^{\delta-}$ species, exploration on hydride-like $\mathrm{NH}_{2}{ }^{\delta-}$ species generated over metal oxide catalysts to facilitate reductive amination is of strong interest. Very recently, we found that a core-shell structured Co@CoO catalyst with $\mathrm{CoO}$ shell having oxygen vacancy is the real active site and enables the dissociation of $\mathrm{H}_{2}$ to yield active $\mathrm{H}^{\delta-}$ species. ${ }^{36}$ Along this line, the potential of the $\mathrm{CoO}$ shell to drive the dissociation of $\mathrm{NH}_{3}$ deserves special attention. 
Here, we found that the hydride-like $\mathrm{NH}_{2}{ }^{\delta-}$ species dissociated on a core-shell structured Co@CoO catalyst favors the reductive amination. This catalyst is efficient for the reductive amination of various substrates to produce corresponding primary amines, outperforming most of the metal-based catalysts. Through density functional theory (DFT) calculations and $\mathrm{D}_{2}$ isotopic experiments, we provided the direct evidence that hydride-like $\mathrm{NH}_{2}{ }^{\delta-}$ species was indeed involved in ammonolysis of the Schiff bases and an in-depth understanding of why the hydride-like $\mathrm{NH}_{2}{ }^{\delta-}$ species can promote the reductive amination so efficiently from molecule collision theory.

\section{Results and discussion}

\section{Identification of core-shell structure of Co@CoO}

The core-shell structured Co@CoO catalyst was prepared with co-precipitation followed by reduction at $250{ }^{\circ} \mathrm{C}$ for $2 \mathrm{~h}$ under $10 \% \mathrm{H}_{2}-90 \% \mathrm{Ar}$ atmosphere. The characterizations by XRD, TEM and EPR were collected in Figure 1 to confirm its structure and surface property. The broad peaks at $41.6^{\circ}$ and $47.5^{\circ}$ are assigned to (100) and (101) planes of Hexagonal Cobalt (JCPDS 05-0727), and the peaks at $44.2^{\circ}$ and $75.8^{\circ}$ are attributed to (111) and (220) planes of Cubic Cobalt (JCPDS 15-0806). Two weak diffraction peaks at $36.5^{\circ}$ and $61.5^{\circ}$ are corresponded to (111) and (220) of cubic CoO (JCPDS 43-1004). These observations suggest that $\mathrm{Co}$ and $\mathrm{CoO}$ co-exist in the catalyst (Figure 1a). The TEM image shows that the outer surface exposes the crystal plane of $\mathrm{CoO}$ and the inside presents the structure of Cubic and Hexagonal Co, clearly proving its core-shell structure (Figure 1b). Furthermore, X-band continuous wave electron paramagnetic resonance (EPR) spectrum was collected at $77 \mathrm{~K}$ to detect the oxygen vacancy of $\mathrm{Co@CoO}$ (Figure 1c). The signal at g=2.00 is assigned to the 
oxygen vacancies, demonstrating its rich surface oxygen vacancies. In short, the above all results confirmed that Co@CoO presents a core-shell structure and the CoO shell is decorated with oxygen vacancies.
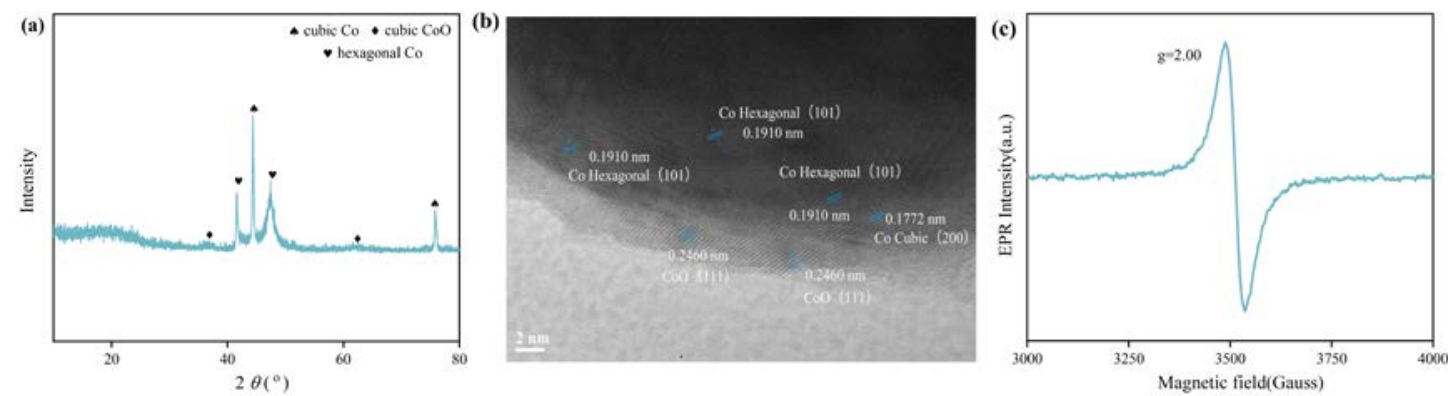

Fig. 1. Characterizations of Co@CoO. (a) XRD pattern; (b) TEM image and (c) X-band EPR spectrum recorded at $77 \mathrm{~K}$.

\section{Identification of dissociation of $\mathrm{H}_{2}$ and $\mathrm{NH}_{3}$ over $\mathrm{Co} @ \mathrm{CoO}$}

Then, in-situ DRIFTS experiments were conducted to verify the dissociation of $\mathrm{H}_{2}$ and explore the dissociation of $\mathrm{NH}_{3}$ on the $\mathrm{Co@CoO}$ surface (Figure 2a and 2b). Upon the introduction of $\mathrm{H}_{2}$ into the gas cell, the band at $1000 \mathrm{~cm}^{-1}$ assigning to the Co-H band appeared, indicating the dissociation of $\mathrm{H}_{2}$ on the $\mathrm{CoO}$ shell (Figure 2a). When introducing $\mathrm{D}_{2}$ gas into the gas cell, the Co-H band and the O-H stretching vibration peaks disappeared, meanwhile the peak of O-D bonding at $2000-2600 \mathrm{~cm}^{-1}$ appeared, accordingly confirming that the heterolytic cleavage of $\mathrm{H}_{2}$ really occurs on the $\mathrm{CoO}$ surface of $\mathrm{Co@CoO}$ catalyst, in good agreement with our previous finding. ${ }^{36}$ 

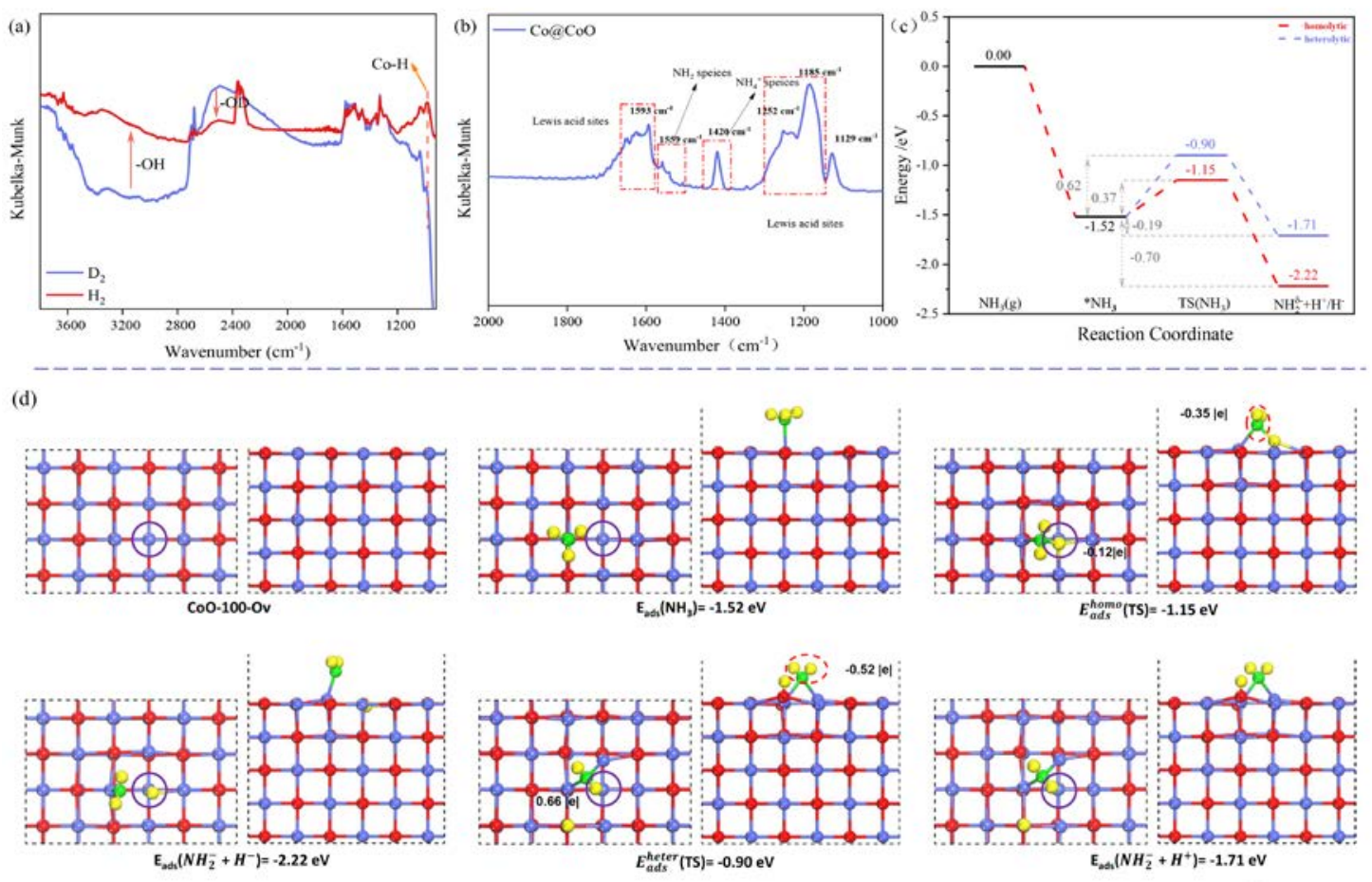

Fig. 2. (a) In situ DRIFTS of $\mathrm{Co@CoO}$ under $\mathrm{H}_{2} / \mathrm{D}_{2}$ gas atmosphere. (b) $\mathrm{NH}_{3}$-adsorption DRIFT spectra of Co@CoO. (c-d) Calculated structures of homolysis and heterolytic $\mathrm{NH}_{3}$ on CoO (100); Adsorption $\mathrm{NH}_{3}$, TS of homolysis $\mathrm{NH}_{3}$ (E $E_{\text {ads }}^{\text {homo }}$ (TS)), TS of heterolytic $\mathrm{NH}_{3}$ ( $E_{\text {ads }}^{\text {heter }}(\mathrm{TS})$ ), final state of homolysis $\mathrm{NH}_{3}\left(\mathrm{NH}_{2}^{-}+\mathrm{H}^{-}\right)$, and final state of heterolytic $\mathrm{NH}_{3}$ $\left(\mathrm{NH}_{2}^{-}+\mathrm{H}^{+}\right)$.

With the introduction of $\mathrm{NH}_{3}$ gas into the gas cell (Figure 2b), six bands were clearly distinguished: the bands at $1593 \mathrm{~cm}^{-1}, 1252 \mathrm{~cm}^{-1}$ and $1185 \mathrm{~cm}^{-1}$ are assigned to the molecule $\mathrm{NH}_{3}$ coordinated to an electron-deficient metal atom (CoOx species) ${ }^{37}$; the peak at $1129 \mathrm{~cm}^{-1}$ is ascribed to the hydrogen bonding formed by the coupling of nitrogen atom with hydrogen of surface hydroxyl groups; and the band at $1420 \mathrm{~cm}^{-1}$ is considered to be $\mathrm{NH}_{4}{ }^{+}$ions produced by the coupling of surface Brönsted sites with $\mathrm{NH}_{3}{ }^{38,39}$ Importantly, the band at $1559 \mathrm{~cm}^{-1}$ corresponding to the $\mathrm{NH}_{2}{ }^{\delta-}$ species appeared, clearly signifying that $\mathrm{NH}_{3}$ is dissociated to afford the surface $\mathrm{Co}-\mathrm{NH}_{2}$ and $\mathrm{O}-\mathrm{H}$ species over the $\mathrm{CoO}$ shell. ${ }^{38,40-42}$ These findings provide strong evidence that the $\mathrm{CoO}$ shell indeed enables the dissociation of $\mathrm{H}_{2}$ and $\mathrm{NH}_{3}$ simultaneously. We 
suspected that the dissociated hydride-like $\mathrm{NH}_{2}{ }^{\delta-}$ species are favorable for the Schiff base ammonolysis, thus resulting in the superior activity of Co@CoO catalyst.

Next, DFT calculations (Figure 2c and Figure 2d) were performed to comparatively investigate the homolytic and heterolytic cleavage of $\mathrm{NH}_{3}$ over $\mathrm{CoO}$ (100) with oxygen vacancies. For the homolytic cleavage of $\mathrm{NH}_{3}$ to $\mathrm{H}^{\delta-}$ and hydride-like $\mathrm{NH}_{2}{ }^{{ }^{-}-}$, the process is strongly exothermic by $0.70 \mathrm{eV}$ and gives a barrier of only $0.37 \mathrm{eV}$, indicating its great feasibility in both thermodynamics and kinetics. By sharp contrast, the heterolytic cleavage to $\mathrm{H}^{\delta+}$ and hydride-like $\mathrm{NH}_{2}{ }^{{ }^{-}-}$is only exothermic by $0.19 \mathrm{eV}$ and has to overcome a higher barrier of $0.62 \mathrm{eV}$. Comparison of the two energy profiles clearly demonstrates that over the CoO shell, the homolytic cleavage of $\mathrm{NH}_{3}$ to $\mathrm{H}^{\delta-}$ and hydride-like $\mathrm{NH}_{2}{ }^{\delta-}$ is of obvious dominance compared with the heterolytic cleavage.

\section{Activity and stability of Co@CoO in reductive amination}

The above results confirm that the core-shell structured Co@CoO catalyst with oxygen vacancies enables the homolytic cleavage of $\mathrm{NH}_{3}$ to $\mathrm{H}^{\delta-}$ and hydride-like $\mathrm{NH}_{2}{ }^{\delta-}$. The catalytic performance of this unique Co@CoO catalyst for the reductive amination was tested and three common reductive aminations of biomass-derived compounds (cyclopentanone, benzaldehyde and furfural) over Co@CoO were investigated (Figure 3a). For the reductive aminations of cyclopentanone and benzaldehyde, Co@CoO shows two times higher productivities and lower temperatures than that of any other reported metal-based catalysts, including noble-metal-based catalysts. For the reductive amination of furfural, Co@CoO also outperforms most of the metalbased catalysts and its productivities is only lower than that of $\mathrm{Ru}_{1} / \mathrm{NC} / \mathrm{Nb}_{2} \mathrm{O}_{5}$, a single-atom catalyst since $\mathrm{Ru}_{1} / \mathrm{NC} / \mathrm{Nb}_{2} \mathrm{O}_{5}$ allows the maximum possible atom economy. Although Raney 
Co shows a slight advantage in productivities, higher temperature is required to overcome the reaction energy barrier. Unequivocally, these results clearly demonstrate the overwhelming efficiency of $\mathrm{Co@CoO}$ catalyst compared with almost all emerging metal-based catalysts in common reductive aminations, probably because of its unique role of hydride-like $\mathrm{NH}_{2}{ }^{{ }^{-}}$ species dissociated on the $\mathrm{CoO}$ shell. Applicability of $\mathrm{Co@CoO}$ towards the reductive amination of various substituents including aromatic and aliphatic aldehydes/ketones was also investigated (Figure 3b). Encouragingly, Co@CoO affords high yields (>94\%) of primary amines for all reactions tested. Noteworthy, the conversion of aromatic aldehydes/ketones with electron-withdrawing and minor electron-donating substituents, such as $\mathrm{F}, \mathrm{Cl}, \mathrm{Br}$ and $\mathrm{CH}_{3} \mathrm{O}$ species, worked well in high yields of 94\%-96\%. Moreover, desired reactivity was achieved when the aliphatic aldehydes and ketones with various aliphatic chains as the substrates. Even Co@CoO is able to perform the reductive amination of biomass-derived furfural to furfuryl amine (98\% yield), which is a significantly important process in biomass valorization, in a yield of $98 \%$. Then we explored its application in the reductive amination of biologically active molecules, and the selective conversion of 4-, 2-methoxyphenylacetone, nabumetone and Stanolone to their corresponding primary amines was realized. In short, these results fully confirm the broad utility of Co@CoO to catalyze reductive amination. 

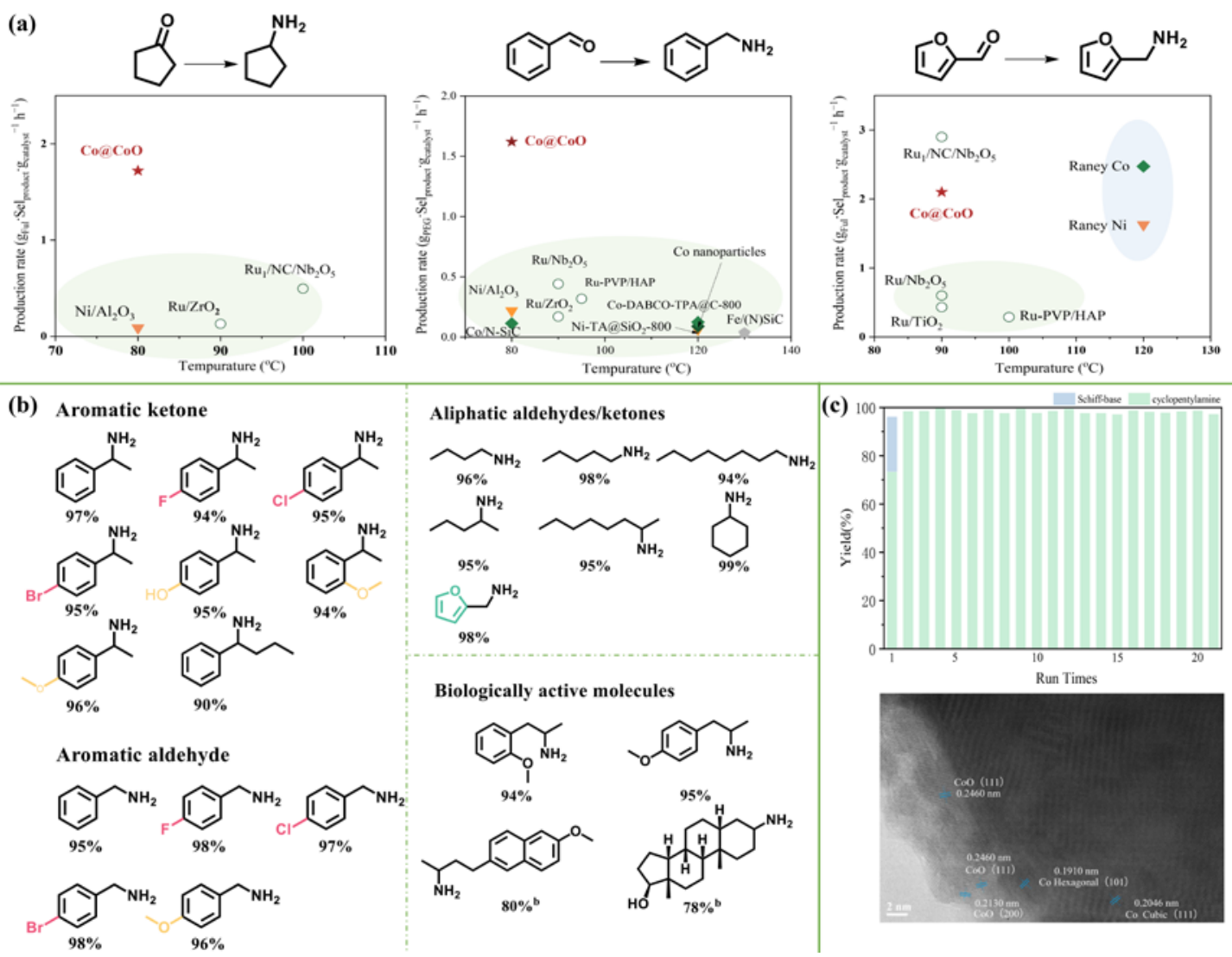

Fig. 3. (a) The catalytic performance of reductive amination between Co@CoO and other catalysts. ${ }^{11,16,17,19,20,22-27,43-45}$ (b) Reductive amination of aliphatic substituted ketones and aldehydes to primary amines. Reaction conditions: 20 mg Co@CoO catalyst, 2 mmol substrates, $100{ }^{\circ} \mathrm{C}, 0.4 \mathrm{MPa} \mathrm{NH}_{3}, 2 \mathrm{MPa} \mathrm{H}_{2}, 5 \mathrm{ml} \mathrm{CH} \mathrm{CH}_{3} \mathrm{OH}$, GC yield with 1,4-dioxane as internal standard; a, GC yield with 1,4-dioxane as solvent and dodecane as internal standard; b, isolated yields of converted hydrochloride salts. (c) Catalyst stability of $\mathrm{Co@CoO}$ for the amination of cyclopentanone and the TEM image of the 21 times-used catalyst.

Considering the simple structure of cyclopentanone, its conversion was selected as a probe reaction to study the catalyst stability and catalytic mechanism. We performed the stability test of $\mathrm{Co} @ \mathrm{CoO}$ and found that the catalyst can be reused 21 times without any deactivation in catalytic performance (Figure 3c). Interestingly, the activity has increased after the first test, probably because the catalyst undergoes surface reconstruction to generate more active surface sites. TEM images (Figure $3 c$ and Figure 1b) show no obvious difference 
between fresh and used Co@CoO and only the CoO shell became deeper. Consequently, the great stability of Co@CoO will bring an attractive future in industrial application.

\section{The unique role of the hydride-like $\mathrm{NH}_{2}{ }^{\delta-}$ species}

(a)

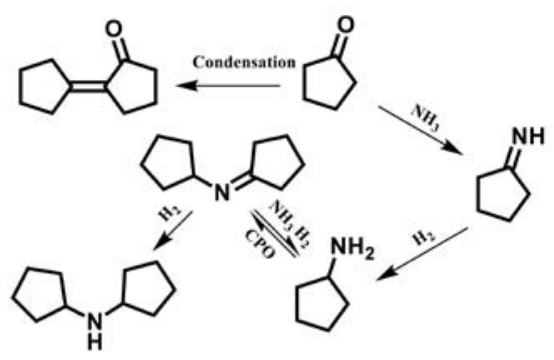

(b)
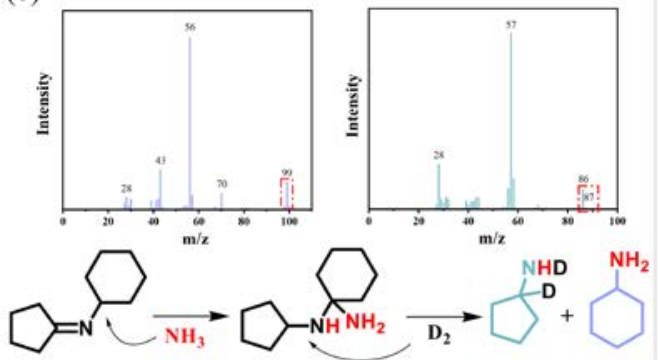

(c)

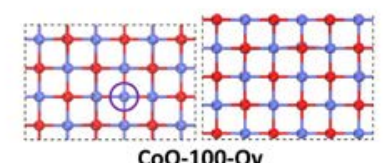

CoO-100-Ov

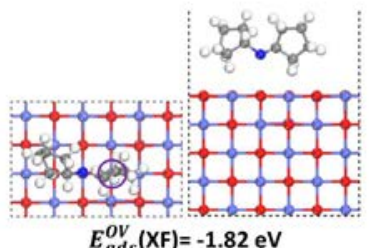

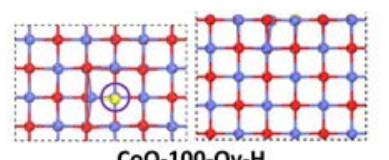

CoO-100-Ov-H

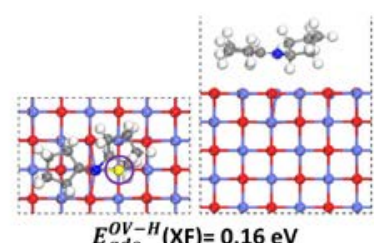

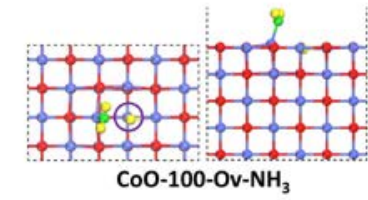

CoO-100-Ov- $\mathrm{NH}_{3}$

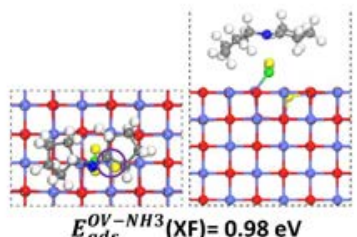

Fig. 4. (a) The possible reaction route for amination of cyclopentanone (CPO). (b) Schiff bases ammonolysis under $D_{2 .}$ (c) Calculated adsorption structures of Schiff baseon reduced CoO (100) surfaces. (Schiff base, $\mathrm{H}^{-}+$Schiff base and $\mathrm{NH}_{2}{ }^{{ }^{-}}{ }^{-}$ads + Schiff base) .

The following emphasis was placed on the exploration of the unique role of the hydridelike $\mathrm{NH}_{2}{ }^{\delta-}$ species. The time course (Figure S1) shows that the yield of Schiff base tends to increase at the first $4 \mathrm{~h}$, then gradually converts into target product, cyclopentylamine with the prolonging of reaction time. It indicates that the Schiff base is indeed the key intermediate and its further conversion is able to determine the whole rate of the reductive amination. Previous reports revealed that the conversion of Schiff base into primary amine includes two steps, namely the addition of Schiff bases with $\mathrm{NH}_{3}$ to geminal diamine and subsequent 
hydrogenolysis to produce primary amine (Figure 4a). ${ }^{15}$ Hydrogen-deuterium exchange experiments were conducted to understand the reaction mechanism (Figure $4 \mathrm{~b})$. Under $\mathrm{D}_{2}$ and $\mathrm{NH}_{3}$, the Schiff bases were converted into cyclohexylamine and two deuteriums-isotopic cyclopentylamine. The molecular ion peak of cyclopentylamine (CPA) has increased from 85 to 87 , suggesting that $\mathrm{D}_{2}$ was added into the $\mathrm{C}=\mathrm{N}$ group of Schiff base. We speculate that the $\mathrm{H}$ of -NHD is not stable, so the fragment peak at 87 was extremely weak and the fragment peak at 86 was stronger (Figure $4 \mathrm{~b}$ ). Clearly, no $\mathrm{D}_{2}$ attacked the cyclohexane part, indicating that the $\mathrm{NH}_{2}{ }^{\delta-}$ species attacked the $\mathrm{C}^{+}$position of $\mathrm{C}-\mathrm{N}$, instead of $\mathrm{C}=\mathrm{N}$ of Schiff base. This result confirmed that the $\mathrm{NH}_{2}{ }^{{ }^{-}-}$species as an active hydride-like species indeed participated in the ammonolysis of Schiff base. To our knowledge, no evidence to prove the $\mathrm{H}^{\delta-}$ species directly take part in the hydrogen/hydrogenolysis reaction was reported until now, although $\mathrm{H}^{\delta-}$ species was believed to be highly active. Obviously, we provide convincing evidence that the hydridelike $\mathrm{NH}_{2}{ }^{\delta}$-species is directly involved in the reaction, which could indirectly indicate the $\mathrm{H}^{\delta \text { - }}$ species involving the hydrogen/hydrogenolysis reaction and boost the research of $\mathrm{H}_{2}$ heterolysis.

We are now in a position to elucidate the key role of the hydride-like $\mathrm{NH}_{2}{ }^{\delta-}$ species through DFT calculations (Figure 4c and Figure S2). With the introduction of $\mathrm{H}_{2}$ and $\mathrm{NH}_{3}$, three possible species including the clean $\mathrm{CoO}$ surface with oxygen vacancies (species $\mathbf{1}$ ), the one formed via the adsorption of $\mathrm{H}^{\delta-}$ species on the reduced $\mathrm{CoO}$ surface (species 2 ) and the species from the co-adsorption of $\mathrm{H}^{\delta-}$ and $\mathrm{NH}_{2}{ }^{\delta-}$ species on the reduced $\mathrm{CoO}$ surface (species 3) exist in reaction system (Figure 4c). Comparison of adsorption energy of three species demonstrates that species $\mathbf{3}$ is of distinctive advantage in thermodynamics, implying that the homolytic 
cleavage of $\mathrm{NH}_{3}$ to $\mathrm{NH}_{2}{ }^{{ }^{-}-}$and $\mathrm{H}^{-}$occurs easily to generate the most stable intermediate to drive the following catalytic cycle. Furthermore, we quantitatively calculated the adsorption energies of Schiff base on the three intermediates. The results show that the adsorption on species $\mathbf{3}$ is strongly endothermic by $0.98 \mathrm{eV}$, larger than that on species $2(0.16 \mathrm{eV})$. By marked contrast, $1.82 \mathrm{eV}$ is released when the adsorption sites resided on species $\mathbf{1}$. These calculations disclose that species $\mathbf{3}$ afford the weakest adsorption to Schiff base. It is therefore reasonable to believe that the extremely weak adsorption allows the Schiff base to move freely on the surface of the stable species 3, providing an in-depth explanation of why hydride-like $\mathrm{NH}_{2}{ }^{\delta-}$ species can facilitate the reductive amination such uniquely from molecule collision theory.

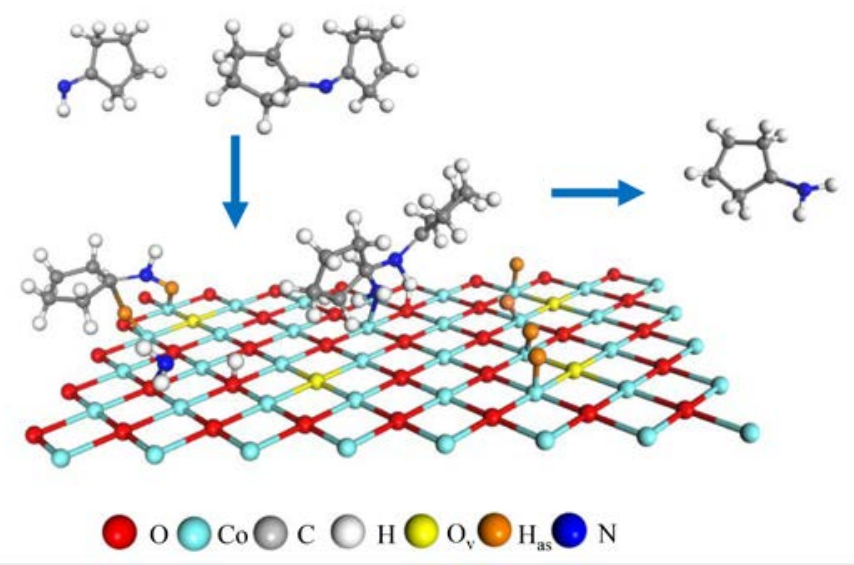

Fig. 5. The possible reaction mechanism of imine hydrogenation and aminolysis of Schiff base. Based on the above results, we proposed the mechanism of the ammonolysis of Schiff base (Figure 5). Firstly, the dissociated the hydride-like $\mathrm{NH}_{2}{ }^{\delta-}$ species and $\mathrm{H}^{-}$over $\mathrm{Co} @ \mathrm{CoO}$ attacked the $\mathrm{C}$ and $\mathrm{N}$ atoms on $\mathrm{C}-\mathrm{N}$ groups of Schiff base, respectively, thus forming the corresponding geminal diamine. Then the $\mathrm{H}^{-}$species from $\mathrm{H}_{2}$ attacked the $\mathrm{C}$ atom of $\mathrm{C}=\mathrm{N}$ groups to produce primary amines, respectively. The $\mathrm{CoO}$ shell not only drives the dissociation of $\mathrm{H}_{2}$ to active $\mathrm{H}^{\delta-}$ species but also enables the homolytic cleavage of $\mathrm{NH}_{3}$.

\section{Conclusion}


In summary, a hydride-like $\mathrm{NH}_{2}{ }^{\delta-}$ species-driven reductive amination was reported and this unique $\mathrm{NH}_{2}{ }^{\delta-}$ species was generated from the dissociation of $\mathrm{NH}_{3}$ over the $\mathrm{CoO}$ shell of core-shell structured Co@CoO catalyst. This unique $\mathrm{NH}_{2}{ }^{{ }^{-}-}$species gives Co@CoO enormous power to convert various substrates to produce corresponding primary amines. This catalyst exhibits considerable performance and excellent stability compared to other emerging metal catalysts during the reductive amination. We revealed that the stable intermediate formed through the co-adsorption of $\mathrm{H}^{\delta-}$ and $\mathrm{NH}_{2}{ }^{\delta-}$ species affords the extremely weak adsorption to Schiff base, accordingly allowing the Schiff base highly active in the molecular collision to present the desired reactivity. This work offers a new insight into the role of hydride-like $\mathrm{NH}_{2}{ }^{\delta-}$ species and deepens the understanding of the dissociation of these hydride-like species involved in many other important reactions.

\section{Methods}

\section{Catalyst preparation}

$\mathrm{Co}_{3} \mathrm{O}_{4}$ was synthesized with a precipitation method. Cobalt nitrate is used as the synthetic precursor. In the typical process, $60 \mathrm{mmol}$ of cobalt nitrate and $69 \mathrm{mmol}$ of $\left(\mathrm{NH}_{4}\right)_{2} \mathrm{CO}_{3}$ was dissolved in $200 \mathrm{ml}$ distilled water, respectively. Then the solution of $\left(\mathrm{NH}_{4}\right)_{2} \mathrm{CO}_{3}$ was added dropwise into the aqueous solution of cobalt salt under vigorous stirring until the $\mathrm{pH}$ of the mother liquid reached approximately 8.5. Finally, the suspension was aged at $65^{\circ} \mathrm{C}$ for $1 \mathrm{~h}$ with stirring and then left to stand at room temperature for $12 \mathrm{~h}$. After filtration and thoroughly washed with distilled water, the solid product was dried at $100^{\circ} \mathrm{C}$ for $12 \mathrm{~h}$ and then calcined in air at $450{ }^{\circ} \mathrm{C}$ for 4 h to obtain $\mathrm{Co}_{3} \mathrm{O}_{4}$. 
The as-prepared $\mathrm{Co}_{3} \mathrm{O}_{4}$ was further reduced at desired temperature $\left(250{ }^{\circ} \mathrm{C}\right)$ for $2 \mathrm{~h}$ under flowing $\mathrm{H}_{2}\left(10 \% \mathrm{H}_{2}-90 \%\right.$ Ar mixed gas) in tube furnace with a ramp of $5{ }^{\circ} \mathrm{C} \cdot \mathrm{min}^{-1}$ before use. Thus-obtained reduced cobalt oxides were marked as Co@CoO.

\section{Catalysts activity tests}

The hydrogenation of propionamide was conducted in a Teflon-lined stainless-steel autoclave $(50 \mathrm{~mL})$. After sealing the desired dosage of propionamide, catalyst, and $\mathrm{CH}_{3} \mathrm{OH}$ in the reactor, the autoclave was purged with $\mathrm{NH}_{3}$ three times and pressurized to the desired pressure. After $\mathrm{NH}_{3}$ purged, the $\mathrm{H}_{2}$ was pressurized to the desired pressure. Then, the autoclave was heated to the predetermined temperature in a short time. After reaction, the reactor was quenched in an ice-water bath immediately.

The liquid phase was separated from the catalyst by centrifugation, and two individual GC/GC-MS systems were used for product analyses. The qualitative analysis of products was carried out on a GC-MS system (Agilent 7890A-5975C).

\section{Catalyst characterization}

Powder X-ray diffraction (XRD) patterns were recorded in the $\theta-2 \theta$ mode on a D8 Focus diffractometer (CuKa1 radiation, $\mathrm{k}=1.5406 \AA$ ), operated at $40 \mathrm{kV}$ and $40 \mathrm{~mA}$ within scattering angels of $10-80^{\circ}$. Transmission electron microscopy (TEM) was obtained on a JEOL Model 2100 electron microscopy at $200 \mathrm{kV}$. The electron paramagnetic resonance (EPR) spectra were collected on a Bruker A300 spectrometer at $77 \mathrm{~K}$.

Diffuse reflectance infrared Fourier transform spectra (DRIFTS) were recorded on a Nicolet Model iS-50 FT-IR spectrometer equipped with an MCT/A detector, and the sample cell was fitted with ZnSe windows. Diffuse reflectance infrared Fourier transform spectra (DRIFTS) 
were recorded on a Nicolet Model iS-50 FT-IR spectrometer equipped with an MCT/A detector, and the sample cell was fitted with ZnSe windows. The DRIFT spectra were recorded with a resolution of $4 \mathrm{~cm}^{-1}$ and 32 scans. For the adsorption and activation of $\mathrm{H}_{2} / \mathrm{D}_{2}$ over Co@CoO catalyst, the as-prepared $\mathrm{Co}_{3} \mathrm{O}_{4}$ was loaded onto DRIFT IR cell, then reduce at $250{ }^{\circ} \mathrm{C}$ for $1 \mathrm{~h}$ under $10 \% \mathrm{H}_{2}-\mathrm{Ar}$ mixed gas. After cooling down to $90{ }^{\circ} \mathrm{C}$ under $\mathrm{Ar}$ atmosphere, the spectrum was recorded as background. Then $\mathrm{H}_{2}$ gas was imputed in the DRFIT cell at $90{ }^{\circ} \mathrm{C}$ for $40 \mathrm{~min}$ and the spectrum was recorded. Finally, $\mathrm{D}_{2}$ gas was flushed into the cell at $90{ }^{\circ} \mathrm{C}$ for another 40 min to record the spectrum. The $\mathrm{NH}_{3}$-DRIFT spectrum was also recorded in the similar procedure. Typically, after cooling down to $90^{\circ} \mathrm{C}, \mathrm{NH}_{3}$ gas was passed through the DRFIT cell for $5 \mathrm{~min}$, then flushed with $\mathrm{Ar}$ at $90^{\circ} \mathrm{C}$ for $20 \mathrm{~min}$ and recorded the spectrum.

\section{Calculation Methods}

In this work, all spin-polarized DFT calculations were carried out using the Vienna Abinitio Simulation Package (VASP) ${ }^{46}$. The projector augmented wave (PAW) method ${ }^{47}$ and the Perdew-Burke-Ernzerhof $(\mathrm{PBE})^{48}$ functional under the generalized gradient approximation $(G G A)^{49}$ were applied throughout the calculations. The kinetic energy cut-off was set to 400 $\mathrm{eV}$, and the force threshold in structure optimization was $0.05 \mathrm{eV} / \AA$. We used a large vacuum gap of $15 \AA$ to eliminate the interactions between neighboring slabs. By adopting these calculation settings, the optimized lattice constant of $\mathrm{CoO}$ is $4.248 \AA$, which is in good agreement with the experimental value of $4.267 \AA^{50}$.

The adsorption energy of species $\mathrm{X}$ on the surface $\left(\mathrm{E}_{\mathrm{ads}}(\mathrm{X})\right)$ was calculated with

$$
E_{\text {ads }}(X)=E_{X / s l a b}-E_{\text {slab }}-E_{X}
$$

where $E_{X / s l a b}$ is the calculated total energy of the adsorption system, while $E_{\text {slab }}$ and $E_{X}$ are calculated energies of the clean surface and the gas phase molecule X, respectively. Obviously, a negative value of $E_{\text {ads }}(X)$ indicates an exothermic adsorption process, and the more negative the $\mathrm{E}_{\text {ads }}(\mathrm{X})$ is, the more strongly the adsorbate $\mathrm{X}$ binds to the surface. 
The oxygen vacancy formation energy $\left(\mathrm{E}_{\mathrm{OV}}\right)$ was calculated according to

$$
E_{\mathrm{OV}}=E_{\text {slab-OV }}+1 / 2 E_{\mathrm{O} 2}-E_{\text {slab }}
$$

where $E_{\text {slab-ov }}$ is the total energy of the surface with one oxygen vacancy, and $E_{02}$ is the energy of a gas phase $\mathrm{O}_{2}$ molecule.

For the model construction, we built a $p(2 \times 3)$ surface slab containing five atomic layers for the $\mathrm{CoO}(100)$ surface, and the top four $\mathrm{CoO}$ layers of the $\mathrm{CoO}(100)$ were allowed to fully relax, while the bottom atomic layers were kept fixed to mimic the bulk region. A $2 \times 2 \times 1 k$ point mesh was used in calculations of all these models. Note that the on-site Coulomb interaction correction is necessary for the appropriate description of the Co $3 d$ electrons, and all calculations are performed with $\mathrm{U}=5.1 \mathrm{eV}$ and $\mathrm{J}=1.0 \mathrm{eV}$, which are consistent with the values determined by previous studies ${ }^{51,52}$.

In addition, we tested the effect of the spin state of $3 d$ electrons in $\mathrm{Co}^{2+}$ in the optimization of $\mathrm{CoO}$, and found that the high-spin antiferromagnetic arrangement was the most stable state, and the calculated magnetic moment of $2.74 \mu \mathrm{B}$ obtained from the difference in spin-up and spin-down densities is consistent with literature reports ${ }^{53-55}$.

Date availability. The data supporting the findings of this study are available within the article, or available from the authors upon reasonable request.

\section{References}

1. Murugesan, K. et al. Catalytic reductive aminations using molecular hydrogen for synthesis of different kinds of amines. Chem. Soc. Rev. 49, 6273-6328 (2020).

2. Froidevaux, V., Negrell, C., Caillol, S., Pascault, J.-P. \& Boutevin, B. Biobased Amines: From Synthesis to Polymers; Present and Future. Chem. Rev. 116, 14181-14224 (2016).

3. Afanasyev, O. I., Kuchuk, E., Usanov, D. L. \& Chusov, D. Reductive Amination in the Synthesis of Pharmaceuticals. Chem. Rev. 119, 11857-11911 (2019).

4. Senthamarai, T. et al. Simple ruthenium-catalyzed reductive amination enables the 
synthesis of a broad range of primary amines. Nat. Commun. 9, 4123 (2018).

5. Pelckmans, M., Renders, T., Van de Vyver, S. \& Sels, B. F. Bio-based amines through sustainable heterogeneous catalysis. Green Chem. 19, 5303-5331 (2017).

6. Niu, F. et al. A multifaceted role of a mobile bismuth promoter in alcohol amination over cobalt catalysts. Green Chem. 22, 4270-4278 (2020).

7. Irrgang, T. \& Kempe, R. Transition-Metal-Catalyzed Reductive Amination Employing Hydrogen. Chem. Rev. 120, 9583-9674 (2020).

8. Gomez, S., Peters, J. A. \& Maschmeyer, T. The Reductive Amination of Aldehydes and Ketones and the Hydrogenation of Nitriles: Mechanistic Aspects and Selectivity Control. Adv. Synth. Catal. 344, 1037-1057 (2002).

9. Liang, G. et al. Production of Primary Amines by Reductive Amination of BiomassDerived Aldehydes/Ketones. Angew. Chem., Int. Ed. 56, 3050-3054 (2017).

10. Deng, D., Kita, Y., Kamata, K. \& Hara, M. Low-Temperature Reductive Amination of Carbonyl Compounds over Ru Deposited on Nb2O5•nH2O. ACS Sustain. Chem. Eng. 7, 4692-4698 (2019)

11. Qi, H. F. et al. Highly selective and robust single-atom catalyst Ru-1/NC for reductive amination of aldehydes/ketones. Nat. Commun. 12, 3295 (2021).

12. Wang, T. et al. Rational design of selective metal catalysts for alcohol amination with ammonia. Nat. Catal. 2, 773-779 (2019).

13. Pera-Titus, M. \& Shi, F. Catalytic Amination of Biomass-Based Alcohols. ChemSusChem 7, 720-722 (2014).

14. Guo, W., Tong, T., Liu, X., Guo, Y. \& Wang, Y. Morphology-Tuned Activity of Ru/Nb2O5 
Catalysts for Ketone Reductive Amination. ChemCatChem 11, 4130-4138 (2019).

15. Dong, B. et al. Heterogeneous Ru-Based Catalysts for One-Pot Synthesis of Primary Amines from Aldehydes and Ammonia. Catalysts 5, 2258-2270 (2015).

16. Nishimura, S., Mizuhori, K. \& Ebitani, K. Reductive amination of furfural toward furfurylamine with aqueous ammonia under hydrogen over Ru-supported catalyst. Res. Chem. Intermed. 42, 19-30 (2016).

17. Komanoya, T., Kinemura, T., Kita, Y., Kamata, K. \& Hara, M. Electronic Effect of Ruthenium Nanoparticles on Efficient Reductive Amination of Carbonyl Compounds. J. Am. Chem. Soc. 139, 11493-11499 (2017).

18. Nakamura, Y., Kon, K., Touchy, A. S., Shimizu, K.-I. \& Ueda, W. Selective Synthesis of Primary Amines by Reductive Amination of Ketones with Ammonia over Supported Pt catalysts. ChemCatChem 7, 921-924 (2015).

19. Liang, G. et al. Production of Primary Amines by Reductive Amination of BiomassDerived Aldehydes/Ketones. Angew. Chem., Int. Ed. 129, 3096-3100 (2017).

20. Chatterjee, M., Ishizaka, T. \& Kawanami, H. Reductive amination of furfural to furfurylamine using aqueous ammonia solution and molecular hydrogen: an environmentally friendly approach. Green Chem. 18, 487-496 (2016).

21. Haskelberg, L. Aminative Reduction of Ketones. J. Am. Chem. Soc. 70, 2811-2812 (1948).

22. Murugesan, K., Beller, M. \& Jagadeesh, R. V. Reusable Nickel Nanoparticles-Catalyzed Reductive Amination for Selective Synthesis of Primary Amines. Angew. Chem., Int. Ed. 58, 5064-5068 (2019).

23. Hahn, G., Kunnas, P., De Jonge, N. \& Kempe, R. General synthesis of primary amines via 
reductive amination employing a reusable nickel catalyst. Nat. Catal. 2, 71-77 (2019).

24. Yuan, H. et al. Reductive Amination of Furanic Aldehydes in Aqueous Solution over Versatile NiyAlOx Catalysts. ACS Omega. 4, 2510-2516 (2019).

25. Chen, W. et al. Preparation of 5-(Aminomethyl)-2-furanmethanol by direct reductive amination of 5-Hydroxymethylfurfural with aqueous ammonia over the Ni/SBA-15 catalyst. J. Chem. Technol. Biotechnol. 93, 3028-3034 (2018).

26. Jagadeesh, R. V. et al. MOF-derived cobalt nanoparticles catalyze a general synthesis of amines. Science 358, 326-332 (2017).

27. Senthamarai, T. et al. Ultra-small cobalt nanoparticles from molecularly-defined Co-salen complexes for catalytic synthesis of amines. Chem. Sci. 11, 2973-2981 (2020).

28. Zhuang, X., Liu, J., Zhong, S. \& Ma, L. Selective catalysis for the reductive amination of furfural toward furfurylamine by graphene-co-shelled cobalt nanoparticles. Green Chem. 24. 271-284 (2022).

29. Jagadeesh, R. V. et al. MOF-derived cobalt nanoparticles catalyze a general synthesis of amines. Science 358, 326 (2017).

30. Lent, R. v. et al. Site-specific reactivity of molecules with surface defects\&\#x2014;the case of H2 dissociation on Pt. Science 363, 155-157 (2019).

31. Liu, P. et al. Photochemical route for synthesizing atomically dispersed palladium catalysts. Science 352, 797-800 (2016).

32. Ye, T.-N. et al. Stable single platinum atoms trapped in sub-nanometer cavities in 12CaO·7Al2O3 for chemoselective hydrogenation of nitroarenes. Nat. Commun.11, 1020 (2020). 
33. Li, S. et al. Selective hydrogenation of 5-(hydroxymethyl)furfural to 5-methylfurfural over single atomic metals anchored on Nb2O5. Nat. Commun.12, 584 (2021).

34. Zhang, S. et al. Solid frustrated-Lewis-pair catalysts constructed by regulations on surface defects of porous nanorods of CeO2. Nat. Commun. 8, 15266 (2017).

35. 35 Zhang, Z. et al. Metal-Free Ceria Catalysis for Selective Hydrogenation of Crotonaldehyde. ACS Catal. 10, 14560-14566 (2020).

36. Xiang, S. et al. Co@CoO: a Unique Catalyst for Hydrogenolysis of Biomass-derived 5Hydroxymethylfurfural to 2,5-Dimethylfuran. DOI:10.26434/chemrxiv-2021-tjsr8.

37. Ramis, G. et al. Adsorption, Activation, and Oxidation of Ammonia over SCR Catalysts. J. Catal. 157, 523-535 (1995).

38. Tamm, S., Vallim, N., Skoglundh, M. \& Olsson, L. The influence of hydrogen on the stability of nitrates during H-2-assisted SCR over Ag/Al2O3 catalysts - A DRIFT study. J. Catal. 307, 153-161 (2013).

39. Sun, D., Liu, Q., Liu, Z., Gui, G. \& Huang, Z. Adsorption and oxidation of NH3 over V2O5/AC surface. Appl. Catal., B 92, 462-467 (2009).

40. Tsyganenko, A. A., Pozdnyakov, D. V. \& Filimonov, V. N. Infrared study of surface species arising from ammonia adsorption on oxide surfaces. J. Mol. Struct. 29, 299-318 (1975).

41. Zhu, Y., Zhang, Y., Xiao, R., Huang, T. \& Shen, K. Novel holmium-modified Fe-Mn/TiO2 catalysts with a broad temperature window and high sulfur dioxide tolerance for lowtemperature SCR. Catal. Commun. 88, 64-67 (2017).

42. Klukowski, D. et al. On the mechanism of the SCR reaction on Fe/HBEA zeolite. Appl. Catal., B 93, 185-193 (2009). 
43. Elfinger, M. et al. Co-Catalyzed Synthesis of Primary Amines via Reductive Amination employing Hydrogen under very mild Conditions. ChemSusChem 14, 2360-2366 (2021).

44. Bäumler, C., Bauer, C. \& Kempe, R. The Synthesis of Primary Amines through Reductive Amination Employing an Iron Catalyst. ChemSusChem 13, 3110-3114 (2020).

45. Zhou, K. et al. Selective Synthesis of Furfurylamine by Reductive Amination of Furfural over Raney Cobalt. ChemCatChem 11, 5562-5569 (2019).

46. Kresse, G. et al. Efficient iterative schemes for ab initio total-energy calculations using a plane-wave basis set. Phys. Rev. B 54, 11169-11186 (1996).

47. Blöchl, P. E. Projector augmented-wave method. Phys. Rev. B 50, 17953-17979 (1994).

48. Perdew, J. P. et al. Generalized gradient approximation made simple. Phys. Rev. Lett. 77, 3865-3868 (1996).

49. Teter, M. P. et al. Solution of schrodinger's equation for large systems. Phys. Rev. B 40, 12255-12263 (1989).

50. Redman, M. J. et al. Cobaltous oxide with the zinc blende/wurtzite-type crystal structure. Nature 193, 867-867 (1962).

51. Archer, T. et al. Magnetism of $\mathrm{CoO}$ polymorphs: density functional theory and monte carlo simulations. Phys. Rev. B 78, 014431(2008).

52. Pickett, W. E. et al. Reformulation of the LDA+U method for a local-orbital basis. Phys. Rev. B 58, 1201-1209 (1998).

53. Solovyev, I. V. et al. Is hund's second rule responsible for the orbital magnetism in solids? Phys. Rev. Lett. 80, 5758-5761 (1998).

54. Rödl, C. et al. Quasiparticle band structures of the antiferromagnetic transition-metal 
oxides MnO, FeO, CoO, and NiO. Phys. Rev. B 79, 235114 (2009).

55. Wdowik, U. D. et al. Lattice dynamics of $\mathrm{CoO}$ from first principles. Phys. Rev. B 75, 104306 (2007).

\section{Acknowledgments}

The authors thank the financially supports by the NSFC of China (21832002, 21825301, 22072042, 22172048 and 22102056) and the China Postdoctoral Science Foundation (2021M691011 and 2021TQ0106).

\section{Author Contributions}

Y.Q.W. and Y.X.J. conceived and supervised the project. W.J.G. and Y.Q.W. designed experiments. W.J.G., X.S. and Y.X.J. performed the synthesis, characterisation, catalytic testing and process analysis. Z.Q.W. X.Q.G and Y.X.J. conducted DFT simulation of Schiff base, $\mathrm{H}_{2}$ and $\mathrm{NH}_{3}$ over $\mathrm{CoO}\left(\begin{array}{ll}1 & 0\end{array}\right)$. Y.G. and X.H.L. participated in analysis of DRIFT of H/D and $\mathrm{NH}_{3}$. W.J.G., Y.X.J. and Y.Q.W. wrote the manuscript. All authors participated in discussions and paper preparation.

\section{Competing interests}

The authors declare no competing financial interest. 